\title{
EFFECT OF CANNA INDICA L. EXTRACTS AGAINST CAFFEINE-NICOTINE COADMINISTRATION-INDUCED EXAGGERATION IN TYPE 2 DIABETIC RATS
}

\author{
KUMBHAR SUBHASH $\mathrm{T}^{1,2}$, UNE HEMANT $\mathrm{D}^{3 *}$, KANNUR DAYANAND $\mathbf{M}^{2}$, PATIL SHRINIWAS P $^{2}$ \\ ${ }^{1}$ CRD, PRIST University, Thanjavur, Tamil Nadu, India. ${ }^{2}$ SCES's, Indira College of Pharmacy, Pune, Maharashtra, India \\ ${ }^{3}$ Y. B. Chavan College of Pharmacy, Aurangabad. MH, India. Email: Profsdune@gmail.com
}

Received: 29 December 2016, Revised and Accepted: 23 January 2017

\section{ABSTRACT}

Objective: This study was designed to evaluate the protective effect of Canna indica L., (CI) extract against caffeine-nicotine administration-induced Type 2 diabetes exaggeration in rats.

Methods: A study was conducted for 3 weeks in four rat groups (n=6); viz., Type 2 diabetic control group, a caffeine-nicotine diabetic control group (20 mg/kg, $0.4 \mathrm{mg} / \mathrm{kg}$, i.p. twice daily), and CI extract and caffeine-nicotine treatment group and standard drug-treated caffeine-nicotine diabetic group (glibenclamide, $5 \mathrm{mg} / \mathrm{kg}$, once daily). Type 2 diabetes was induced by 2 weeks high fatty diet and a single dose streptozotocin (50 mg/kg, i.p.) on $1^{\text {th }}$ day of the study in all groups. Blood and urine samples were collected every week for serum biochemical analysis.

Results: Results of extract treatment and standard drug treatment were compared with untreated caffeine-nicotine coadministration group. Difference in each relevant serum parameter was analyzed through ANOVA and Dunett's t-test. Extract-treated caffeine-nicotine-diabetic group showed about $150-200 \mathrm{mg} / \mathrm{dL}(\mathrm{p}<0.001)$ reduction in the serum glucose than untreated caffeine-nicotine-diabetic control (DCN) group. Extract treatment reduces serum glucose by $10-15 \mathrm{mg} / \mathrm{dL}$ than glibenclamide treatment with higher significance $(\mathrm{p}<0.001)$. Extract treatment showed better results than standard drug in liver and kidney function test and exhibited its better potential in controlling diabetic complications. Extract treatment increased high-density lipid-cholesterol and reduced triglycerides, low-density lipid-cholesterol (LDL-C), very LDL-C, and total cholesterol (TC) much better and with higher significance than standard drug. Extract treatment reduced TC by at least $60-80 \mathrm{mg} / \mathrm{dL}$ (p<0.01) in comparison to DCN group. Extract treatment reduced $10-15 \mathrm{mg} / \mathrm{dL}$ of more TC than that of standard drug.

Conclusion: Caffeine-nicotine coadministration-induced exaggeration of Type 2 diabetes was better treated by CI extract than that of standard drug glibenclamide.

Keywords: Type 2 diabetes, Streptozotocin, Caffeine, Nicotine, Diabetic complication, Rat.

(C) 2017 The Authors. Published by Innovare Academic Sciences Pvt Ltd. This is an open access article under the CC BY license (http://creativecommons. org/licenses/by/4. 0/) DOI: http://dx.doi.org/10.22159/ajpcr.2017.v10i4.16845

\section{INTRODUCTION}

Diabetes is called a lifestyle disease. Due to urbanization in late $20^{\text {th }}$ century and early $21^{\text {st }}$ century large population of developing countries is shifting to urban area [1,2]. The people who were living very peaceful life in villages are now facing very hectic lifestyle in urban areas. This change has loaded a huge mental stress on urban population and their present generation [3]. With lifestyle food habits have changed a lot. Simple and pure food now has become much complex and adulterated one. Uncomfortable time schedules, night-shifts, poor hygiene, and lack of physical exercise are observed as reasons for increased incidences of early diabetes [4]. Due to increase in the stress; population has got attracted toward addictions also [5]. Addiction is generally observed for tobacco products, alcohol, other drinks, and drugs. There is a link between diabetes and addictions; particularly, nicotine and alcohol. Tobacco chewing and smoking both are found to increase insulin resistance while alcohol is found to harm pancreatic islets [6]. This link was the major focus of this research.

In our previous study, we demonstrated exaggeration of streptozotocin (STZ)-induced Type 2 diabetes in rats due to caffeine-nicotine coadministration [7]. When we compared diabetic control group with coadministration group we observed increase in insulin resistance, hyperglycemia, and hyperlipidemia. We also demonstrated change in histopathology of vital organs such as pancreas, kidney, and liver of diabetic animals and concluded, "there was mild to moderate exaggeration of organ damage in diabetes due to chronic coadministration of caffeine-nicotine" [7].
Along with the insulin and hypoglycemic drug therapy herbal drugs are being used either as alternative or as adjuvant to the therapy. Herbal drug is known to have several benefits which help significantly in the management of diabetes. They are popular due to ease of availability, lack of potential side effects, and other benefits such as antioxidant activity and nutritional benefits. Use of herbal drugs in diabetes is being practiced all over the world, particularly in developing and poor countries [8]

Rahmatullah et al., in 2009, conducted a survey in Thakurgaon district of Bangladesh where he observed that different tribes residing around use large amount of medicinal plants to cure their diseases. Water extract of Canna indica L. (CI) whole herb was being given orally to treat diabetes [9]. Purintrapiban et al. described differential activation of glucose transporters (GLUT) in cultured muscle cells by polyphenolic compounds from $\mathrm{CI}$ and proposed the interference of these compounds with different GLUT [10]. On this basis, we selected water extract of this plant to treat diabetes and its exaggeration caused by addiction of caffeine and nicotine.

CI is known as "Indian shot" and generally found in gardens as flowering plant. It has been cultivated since historical times at different geographical areas of the world. It is native to South-Central America (Andes), West Indies, Mexico, Europe, Africa and Asia. Flowers of CI plant are the rich source of anthocyanin color pigments. These eatable pigments can be used as antioxidant nutraceutical in food industry [11].

There are numerus ethnopharmacological uses of different parts of CI herb recommended by traditional medical practitioners in Thailand, 
Bangladesh, Philippine, and India. Rhizome is considered diuretic, demulcent, antipyretic, and diaphoretic. Decoction of rhizome is useful in treating dyspepsia, dropsy, hepatitis, and jaundice. Roots are said to be acrid and stimulant [12]. These medicinal activities are traditional beliefs of tribes and they lack proper evidence in the form of clinical documentation.

"How to minimize the additional exaggeration of complication caused by nicotine-caffeine in Type 2 diabetes?" was the main focus of this study $[7,13]$. We treated caffeine-nicotine addicted diabetic animals with standard drug glibenclamide and CI extract in different groups. Results of the extract treatment were statically tested against caffeinenicotine-diabetic control (DCN) group while compared with standard group in the evaluation.

\section{METHODS}

\section{Materials}

Analytical grade chemicals were used throughout the work. Caffeine and nicotine (Tokyo Chemical Industry, Japan), STZ (Sisco Research Lab, Mumbai, India), biochemical estimation kit (Biolab Diagnostics (Pvt.), Ltd., Mumbai, India), and animal feed (Nutrivet Life Sciences, Pune, India) were used.

\section{Methods}

\section{Extract preparation}

Flower bearing plants 2-3 $\mathrm{m}$ in height were collected from botanical garden located in Pune. The CI plant sample selected for the work was submitted and subsequently authenticated by the regional government institute "Botanical Survey of India, Koregaon park, Pune" with voucher code (SK01). Rhizome and roots were dried in a lab for 15 days and powdered using mixer blender. The resulting mass was macerated in ethanol:water (1:1) solvent for 24 hrs [14]. Resultant liquid was concentrated to semi-solid mass by evaporating solvent by rotary evaporator (Evator, South Africa). Concentrate was filled in sterile amber glass bottle. One kilogram of powdered drug gave $9.33 \mathrm{~g}$ of extract (approximately 1\% yield). Extract was stored at cool place and dry place till its administration in rats. Preliminary phytochemical, qualitative and quantitative analysis of this CI extract was performed as per our previous study [15].

\section{Animals used}

Sprague Dawley male rats were procured from Committee for the Purpose of Control and Supervision of Experiments on Animals (CPCSEA) approved supplier, and they were kept in quarantine for 7 days to acclimatize with animal house condition. After acclimatization, animals were shifted to $12 \mathrm{hrs}$ auto-controlled light-dark cycle in a separate room. Except during the experiment, animals were kept on adequate supply of standard diet and purified water. Animals of age 8-10 weeks and body weight 150-200 g were selected randomly for the study.

\section{Antidiabetic activity}

During the experiment, animals were kept on the standard diet and sufficient water. Animals were divided into four groups containing ten animals in each group. All animals were fed with high fat diet (HFD) for 2 weeks and single dose STZ was injected on $1^{\text {st }}$ day to induce Type 2 diabetes [16]. Groups II, III and IV were administered with normal doses of (i.p.) caffeine and nicotine twice daily to produce addiction for 3-week period [17]. On $7^{\text {th }}$ day after STZ administration, six stable animals were selected for further study while four animals were removed from each group. Extract and glibenclamide were suspended in $5 \%$ acacia solution and administered orally in overnight fasted rats by gastric intubation. Group III was treated orally with $200 \mathrm{mg} / \mathrm{kg}$ of CI extract and Group IV was treated with standard drug glibenclamide ( $5 \mathrm{mg} / \mathrm{kg}$, p.o.) once daily for 3 weeks. Group I was plane diabetic control (D), Group II was DCN, Group III was extract-treated caffeinenicotine-diabetic group (EDCN) while Group IV was standard drug glibenclamide-treated caffeine-nicotine-diabetic group (GDCN). Blood samples were drawn from retro orbital sinus weekly till the end of study (i.e., 3 weeks). Fasting blood glucose estimation and body weight measurements were conducted on $1,7,14$, and $21^{\text {st }}$ day of the study. On $21^{\text {st }}$ day animals were anesthetized and sacrificed. Room temperature of $20 \pm 5^{\circ} \mathrm{C}$ and relative humidity of $60 \pm 10 \%$ was maintained throughout the study.

This study was conducted in compliance with guidelines published by the CPCSEA. Approval of the Institutional Animal Ethics Committee (IAEC) was obtained before the initiation of the study (IAEC-16-004). Study was completed within 6 months form the date of approval.

\section{Clinical biochemistry}

Each animal was anesthetized adequately using diethyl ether and blood was withdrawn from orbital plexus by capillary method. Blood was collected in a labeled vial containing sodium heparin anticoagulant. These vials were rotated at $3000 \mathrm{rpm}$ for 15 minutes in a centrifuge (Remi, Mumbai, India) to separate the components of blood. Serum was separated and analyzed using EM density 180 clinical chemistry analyzer (Erba diagnostics, Germany). Ready-to-use reagents were procured to estimate serum levels of glucose, alanine aminotransferase (ALT), aspartate aminotransferase (AST), creatinine (CRE), urea (BU), triglycerides (TG), high-density lipid-cholesterol (HDL-C), low-density lipid-cholesterol (LDL-C), and total cholesterol (TC).

\section{Statistical analysis}

Each group was containing at least six animals to statistically generalize the outcome. Results were presented as mean \pm standard error of mean. Treatment groups were analyzed against different control groups using one-way ANOVA and Dunnett's t post-test. Significance was determined in terms of $\mathrm{p}$ value; and $\mathrm{p}<0.05$ was considered significant. Different levels of significance utilized in the study were ${ }^{a}:(p<0.05),{ }^{b}:(p<0.01)$ and $\mathrm{c}:(\mathrm{p}<0.001)$ for test and $\mathrm{x}:(\mathrm{p}<0.05)$ between control groups.

\section{RESULTS}

\section{Body weight analysis}

Induction of diabetes always leads to acute polyuria in the animal. This polyuria further creates dehydration and weakness. In D group, there was progressive weight loss parallel to diabetes. In DCN group, there was little more weight loss than D group. In EDCN and GDCN groups, there was negligible weight loss compared to the control groups. There was no full weight recovery in any group after diabetes induction even after treatment (Fig. 1).

\section{Clinical biochemistry \\ Serum glucose levels}

Fasting glucose level was estimated in early morning blood of target animals. Diabetic control group rats (D) showed expected rise in serum glucose level and exhibited successful induction of Type 2 diabetes. Caffeine-nicotine diabetic control showed even more increase in glucose level about $50-60 \mathrm{mg} / \mathrm{dL}(\mathrm{p}<0.05)$. Extract treatment group showed progressive reduction in theblood glucose about $150-200 \mathrm{mg} / \mathrm{dL}(\mathrm{p}<0.001)$ less than diabetic caffeine-nicotine group. Glibenclamide-treated GDCN group showed significant $(\mathrm{p}<0.05)$ rise in blood glucose as like extract treatment group. Extract treatment showed better control on average blood glucose than standard drug by 20-30 mg/dL (Fig. 2).

\section{Liver function test}

Serum AST and ALT are metabolic enzymes secreted by liver which were estimated to demonstrate liver function. Diabetic control animals showed progressive increase in AST, ALT levels; approximately 2-3 times greater than that of normal. Group DCN showed much intense rise in AST ALT than plane diabetic group. Extract treatment (in EDCN) reduced concentration of these enzymes in blood better than standard drug treatment (in GDCN) by $30-40 \mathrm{U} / \mathrm{L}(\mathrm{p}<0.01$ ) and $150-200 \mathrm{U} / \mathrm{L}$, respectively, $(\mathrm{p}<0.001)$. Here, also extract showed better control on these levels than that of standard drug (Table 1). 


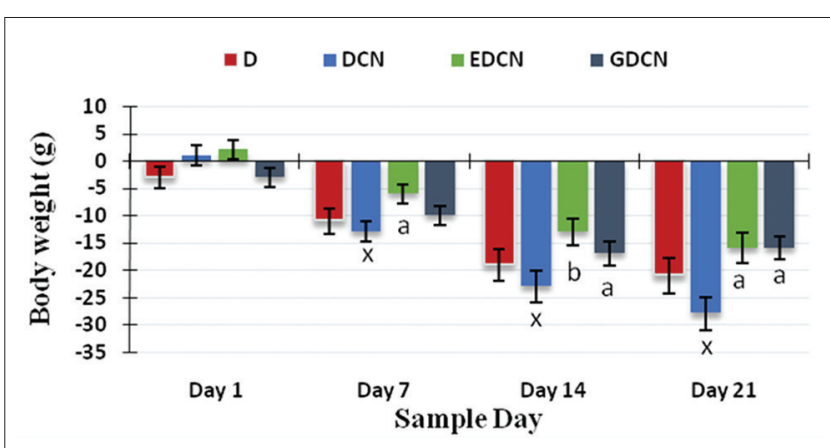

Fig. 1: Body weight changes ( $n=6)$. D: Diabetic control group; DCN: Caffeine-nicotine diabetic group, EDCN: Extract-treated caffeine-nicotine diabetic group. GDCN: Gibenclamide-treated caffeine-nicotine diabetic group. Results expressed as mean \pm standard error of mean and compared with diabetic caffeine-nicotine control group; difference analyzed among groups using one-way ANOVA and Dunnett's t post-test. a Difference between a treatment group and DCN control group significant at $\mathrm{p}<0.05$, bdifference between a treatment group and DCN control group significant at $\mathbf{p}<0.01$, ${ }^{x}$ difference among plane diabetic and caffeine-nicotine diabetic control groups significant at $\mathbf{p}<0.05$

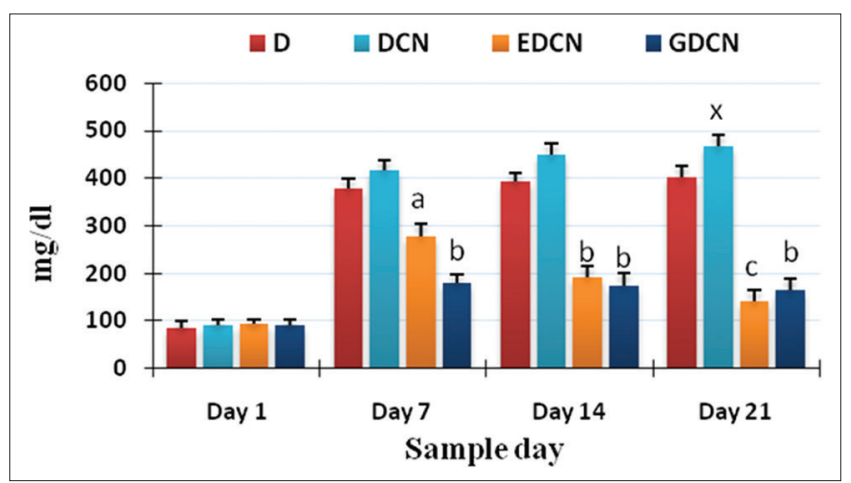

Fig. 2: Serum fasting glucose levels $(n=6)$. D: Diabetic control group; DCN: Caffeine-nicotine diabetic group, EDCN: Extract-treated caffeine-nicotine diabetic group, GDCN: Glibenclamide-treated caffeine-nicotine diabetic group. Results expressed as mean \pm standard error of mean and compared with diabetic caffeine-nicotine control group; Difference analyzed among groups using one-way ANOVA and Dunnett's t post-test. ${ }^{\text {DDifference between two groups }}$ is significant at $\mathbf{p}<0.05$, bdifference between two groups is significant at $\mathbf{p}<0.01$, ${ }^{x}$ difference among plane diabetic and caffeine-nicotine diabetic control groups significant at $p<0.05$

\section{Kidney function test}

Serum urea and CRE levels are indicators of kidney damage in diabetes. DCN group showed more elevation of these levels than plane diabetic control possibly due to additional damage caused by caffeine-nicotine administration. Extract-treated EDCN group showed less kidney damage than that of standard drug-treated GDCN group. About $30-40 \mathrm{mg} / \mathrm{dL}$ of less urea was observed in treatment groups than that of diabetic control groups $(\mathrm{p}<0.001)$ while 0.3-0.4 mg/dL of less CRE was observed in treatment groups than that of control groups $(p<0.01)$. Here, also extract treatment show lesser concentration of urea and CRE in blood compared to standard drug (Table 2).

\section{Lipid profile}

Diabetes being metabolic disorder increases TG in blood called diabetes-induced triglyceridemia. There was marked increase in blood TG level in diabetic control animals.
Triglyceridemia is more in animals with caffeine-nicotine treatment compared to plane diabetic control by about $20 \mathrm{mg} / \mathrm{dL}(\mathrm{p}<0.05)$. Triglyceridemia was much better controlled by the CI herbal extract treatment $(40-50 \mathrm{mg} / \mathrm{dL})$ compared to glibenclamide treatment $(30-40 \mathrm{mg} / \mathrm{dL})$. There was difference of $8-12 \mathrm{mg} / \mathrm{dL}(0.05)$ of $\mathrm{TG}$ between EDCN and GDCN group blood (Table 3).

HDL-C is identified as beneficial cholesterol and it is a marker of healthy normal blood. Diabetes in step-wise manner reduce this cholesterol as evident in both the control groups. Plane diabetic control showed less reduction in HDL-C as compared to caffeine-nicotine administered controlled. Extract treatment promotes approximately $4-6 \mathrm{mg} / \mathrm{dL}$ rise in HDL-C in EDCN group than GCDN group rats. Extract treatment showed clear benefit by promoting good fats, i.e., HDL-C (Table 3).

The LDL-C is generally linked with the cardiovascular complication of the Type 2 diabetes. In plane control group, there was continuous rise in LDL-C during the study period. This rise was still much less than exaggerated rise observed in DCN control group by $15-20 \mathrm{mg} / \mathrm{dL}$ $(p<0.05)$. Extract treatment in EDCN group showed that it greatly reduces this increasing harmful fat, LDL-C though caffeine-nicotine exaggerate it. Extract treatment reduces average $10-12 \mathrm{mg} / \mathrm{dL}(\mathrm{p}<0.01)$ of LDL-C in EDCN rats than that of standard drug-treated GDCN rats (Table 3).

There was additional rise in very LDL-C (VLDL-C) in case of caffeine-nicotine DCN control than that of plane diabetic control D by $12-15 \mathrm{mg} / \mathrm{dL}(\mathrm{p}<0.05)$. As like LDL-C, there was much reduction in VLDL-C due to extract administration in EDCN rats compared to glibenclamide administration in GDCN rats.

There was $8-10 \mathrm{mg} / \mathrm{dL}(\mathrm{p}<0.001)$ more significant reduction of VLDL-C by extract in EDCN compared to one observed in GDCN group (Table 3).

Total serum cholesterol is an important parameter in prediction of cardiovascular complication of diabetes. Caffeine-nicotine exaggerates total serum cholesterol by at least $10-15 \mathrm{mg} / \mathrm{dL}$ over plane diabetic control. Extract treatment brake this rise by at least $60-80 \mathrm{mg} / \mathrm{dL}$ $(p<0.01)$ in comparison to control groups. Extract reduce $10-15 \mathrm{mg} / \mathrm{dL}$ of more cholesterol than that of standard drug as depicted in Fig. 3.

\section{DISCUSSION}

This research protocol was continuation of our previous work Kumbhar et al. where we demonstrated exaggeration of Type 2 diabetes by caffeine nicotine coadministration in diabetic rats [7]. We also conducted another study where we proposed significant antidiabetic activity of CI extract in SD rats [15]. The purpose of this study was to treat caffeine-nicotine exaggerated diabetes in animals using existing standard drug as well as effective dose of $\mathrm{CI}$ extract orally in separate rat groups. This study used HFD/STZ model to induce Type 2 diabetes in SD rats. This study assumes that the caffeine and nicotine injected in animals induce an addiction as they do in human beings.

For diabetes induction, standard diet was mixed with the vegetable source ghee in such a concentration that ghee contributed $40 \%$ calories of the diet. All the groups were fed with this HFD for 2 weeks prior STZ injection. On $7^{\text {th }}$ day, STZ (assay $>98 \%$ ) was diluted in cold citrate buffer and injected intraperitoneally in all rats. The induction of diabetes was confirmed by polyuria and polyphagia produced in animals. Initially, 10 rats were taken in each group and four unstable rats, in terms of glucose level and body weight; were removed from each group. After STZ injection, all rats were maintained on standard pellet diet and sufficient water in air conditioned room where temperature and moisture was maintained with at most care. Because these conditions generally alter hormonal secretions in the animal body and may interfere with the experiment results.

Caffeine (assay >98\%) and nicotine (assay $>95 \%$ ) were measured carefully; diluted in saline and administered intraperitoneally twice daily in their normal doses to create addiction [9]. There was no 
Table 1: Liver function test $(n=6)$

\begin{tabular}{|c|c|c|c|c|c|c|c|c|}
\hline \multirow[t]{2}{*}{ Group } & \multicolumn{4}{|c|}{ ALT levels (U/L) } & \multicolumn{4}{|c|}{ AST levels (U/L) } \\
\hline & Day 1 & Day 7 & Day 14 & Day 21 & Day 1 & Day 7 & Day 14 & Day 21 \\
\hline D & $42 \pm 2.7$ & $81 \pm 5.6$ & $86 \pm 3.1$ & $92 \pm 3.3$ & $123 \pm 9.4$ & $280 \pm 16.4$ & $301 \pm 17.4$ & $311 \pm 19.4$ \\
\hline DCN & $41 \pm 3.0$ & $99 \pm 3.4^{x}$ & $107 \pm 2.9^{x}$ & $113 \pm 3.4^{x}$ & $117 \pm 9.4$ & $307 \pm 13.8$ & $335 \pm 15.4$ & $359 \pm 16.4^{x}$ \\
\hline EDCN & $40 \pm 2.8$ & $61 \pm 2.9^{\mathrm{a}}$ & $54 \pm 2.9^{\mathrm{b}}$ & $59 \pm 3.2^{\mathrm{b}}$ & $119 \pm 8.6$ & $211 \pm 14.3^{\mathrm{b}}$ & $188 \pm 16.4^{\mathrm{b}}$ & $171 \pm 18.7^{\mathrm{c}}$ \\
\hline GDCN & $39 \pm 2.7$ & $68 \pm 2.9$ & $72 \pm 3.0^{\mathrm{a}}$ & $79 \pm 2.8^{\mathrm{a}}$ & $129 \pm 4.5$ & $235 \pm 15.4^{\mathrm{a}}$ & $207 \pm 13.4^{\mathrm{a}}$ & $178 \pm 17.9^{c}$ \\
\hline
\end{tabular}

D: Diabetic control group; DCN: Diabetes and caffeine-nicotine both simultaneously; EDCN:Extract treated caffeine-nicotine diabetic group. GDCN: Glibenclamide treated caffeine-nicotine diabetic group. Results expressed as Mean \pm SEM. Results were compared with diabetic caffeine-nicotine control group; Difference analyzed amongst groups using one-way ANOVA and Dunnett's t post-test. a Difference amongst two groups is significant at $\mathrm{p}<0.05$. ${ }^{\mathrm{b}} \mathrm{Difference}$ amongst two groups is significant at $\mathrm{p}<0.01$. $\mathrm{x}$ Difference amongst plane diabetic and caffeine-nicotine diabetic control groups significant at $\mathrm{p}<0.05$.

Table 2: Kidney function test $(n=6)$

\begin{tabular}{|c|c|c|c|c|c|c|c|c|}
\hline \multirow[t]{2}{*}{ Group } & \multicolumn{4}{|c|}{ Serum urea $(\mathrm{mg} / \mathrm{dL})$} & \multicolumn{4}{|c|}{ Serum creatinine $(\mathrm{mg} / \mathrm{dL})$} \\
\hline & Day 1 & Day 7 & Day 14 & Day 21 & Day 1 & Day 7 & Day 14 & Day 21 \\
\hline $\mathrm{D}$ & $18 \pm 3.2$ & $64 \pm 4.1$ & $67 \pm 4.3$ & $69 \pm 4.4$ & $0.37 \pm 0.04$ & $0.63 \pm 0.05$ & $0.68 \pm 0.05$ & $0.73 \pm 0.05$ \\
\hline DCN & $19 \pm 4.6$ & $67 \pm 4.0$ & $76 \pm 4.1$ & $86 \pm 4.2^{\mathrm{x}}$ & $0.36 \pm 0.04$ & $0.73 \pm 0.04$ & $0.89 \pm 0.05^{\mathrm{x}}$ & $0.96 \pm 0.05^{x}$ \\
\hline EDCN & $17 \pm 4.3$ & $32 \pm 3.9^{\mathrm{b}}$ & $33 \pm 4.1^{\mathrm{b}}$ & $36 \pm 4.0^{c}$ & $0.38 \pm 0.04$ & $0.54 \pm 0.05$ & $0.49 \pm 0.04^{\mathrm{a}}$ & $0.41 \pm 0.04^{\mathrm{b}}$ \\
\hline GDCN & $19 \pm 4.1$ & $31 \pm 3.8^{\mathrm{b}}$ & $28 \pm 4.9^{c}$ & $30 \pm 4.2^{c}$ & $0.31 \pm 0.04$ & $0.65 \pm 0.05$ & $0.74 \pm 0.05$ & $0.71 \pm 0.05$ \\
\hline
\end{tabular}

D: Diabetic control group; DCN: Diabetes and caffeine-nicotine both simultaneously; EDCN:Extract treated caffeine-nicotine diabetic group. GDCN: Glibenclamide treated caffeine-nicotine diabetic group. Results expressed as Mean \pm SEM. Results were compared with diabetic caffeine-nicotine control group; Difference analyzed amongst groups using one-way ANOVA and Dunnett's t post-test. a Difference amongst two groups is significant at $p<0.05$. ${ }^{b}$ Difference amongst two groups is significant at $\mathrm{p}<0.01 . x$ : Difference amongst plane diabetic group and caffeine-nicotine diabetic control group significant at $\mathrm{p}<0.05$.

Table 3: Serum lipid levels $(n=6)$

\begin{tabular}{|c|c|c|c|c|c|c|c|c|}
\hline \multirow[t]{2}{*}{ Group } & \multicolumn{4}{|c|}{ Serum triglycerides $(\mathrm{mg} / \mathrm{dL})$} & \multicolumn{4}{|c|}{ Serum HDL-C (mg/dL) } \\
\hline & Day 1 & Day 7 & Day 14 & Day 21 & Day 1 & Day 7 & Day 14 & Day 21 \\
\hline D & $51 \pm 7.2$ & $80 \pm 7.8$ & $83 \pm 8.2$ & $88 \pm 9.1$ & $53 \pm 3.5$ & $51 \pm 4.1$ & $48 \pm 4.4$ & $44 \pm 4.6$ \\
\hline DCN & $47 \pm 7.3$ & $81 \pm 7.3$ & $98 \pm 7.8$ & $103 \pm 7.2^{x}$ & $49 \pm 3.2$ & $46 \pm 3.8$ & $42 \pm 4.0$ & $38 \pm 3.9^{x}$ \\
\hline EDCN & $53 \pm 7.0$ & $63 \pm 8.3^{\mathrm{a}}$ & $59 \pm 7.7^{\mathrm{b}}$ & $60 \pm 7.6^{\mathrm{b}}$ & $48 \pm 3.4$ & $52 \pm 3.9$ & $57 \pm 3.6^{\mathrm{a}}$ & $56 \pm 3.8^{\mathrm{b}}$ \\
\hline GDCN & $50 \pm 7.6$ & $61 \pm 8.9^{\mathrm{a}}$ & $63 \pm 8.7^{\mathrm{a}}$ & $67 \pm 8.1^{\mathrm{a}}$ & $51 \pm 3.4$ & $53 \pm 3.7$ & $58 \pm 3.4^{\mathrm{a}}$ & $61 \pm 3.7^{b}$ \\
\hline \multirow[t]{2}{*}{ Group } & \multicolumn{4}{|c|}{ Serum LDL-C (mg/dL) } & \multicolumn{4}{|c|}{ Serum VLDL-C (mg/dL) } \\
\hline & Day 1 & Day 7 & Day 14 & Day 21 & Day 1 & Day 7 & Day 14 & Day 21 \\
\hline D & $65 \pm 6$ & $112 \pm 09$ & $119 \pm 11$ & $122 \pm 9$ & $19 \pm 1.3$ & $29 \pm 1.5$ & $31 \pm 1.4$ & $33 \pm 1.6$ \\
\hline DCN & $58 \pm 9$ & $113 \pm 10$ & $128 \pm 8$ & $139 \pm 8^{x}$ & $20 \pm 1.1$ & $34 \pm 1.5$ & $37 \pm 1.4^{x}$ & $40 \pm 1.6^{x}$ \\
\hline EDCN & $67 \pm 7$ & $89 \pm 10^{\mathrm{a}}$ & $81 \pm 9^{b}$ & $072 \pm 9^{b}$ & $21 \pm 1.3$ & $22 \pm 1.2^{\mathrm{a}}$ & $21 \pm 1.1^{\mathrm{b}}$ & $23 \pm 1.2^{c}$ \\
\hline GDCN & $69 \pm 9$ & $80 \pm 07$ & $79 \pm 8^{\mathrm{b}}$ & $83 \pm 11^{\mathrm{b}}$ & $20 \pm 1.3$ & $26 \pm 1.4$ & $27 \pm 1.2$ & $29 \pm 1.3^{a}$ \\
\hline
\end{tabular}

D: Diabetic control group; DCN: Diabetes and caffeine-nicotine both simultaneously; EDCN:Extract treated caffeine-nicotine diabetic group. GDCN: Glibenclamide treated caffeine-nicotine diabetic group. Results expressed as Mean \pm SEM. Results were compared with diabetic caffeine-nicotine control group; Difference analyzed amongst groups using one-way ANOVA and Dunnett's t post-test. 'Difference amongst two groups is significant at $\mathrm{p}<0.05$. ${ }^{\mathrm{b}}$ Difference amongst two groups is significant at $\mathrm{p}<0.01$.x: Difference amongst plane diabetic group and caffeine-nicotine diabetic control group significant at $\mathrm{p}<0.05$.

point in giving these drugs orally as this would have changed their bioavailability due to unpredictable absorption and presystemic metabolism. Their oral stability was another limitation particularly for volatile nicotine.

Based on the literature survey, this is the first study where we treated caffeine-nicotine-induced exaggeration of Type 2 diabetes using herbal drug and compared it with modern allopathic drug. Caffeine-nicotine addiction reduces the response of animals to the glibenclamide while extract suppress this effect of addiction. Hypoglycemic drugs control hyperglycemia but generally cannot control other diabetic complications in effective manner and herbal drugs do better in this situation. If we compare the results of kidney and liver function test; it is evident that extract controlled damage of these organs better than standard drug did. Triglyceridemia is one of the most observed diabetic complications in most patients [18]. Triglyceridemia leads to system acidosis and ketone body formation. These ketone bodies liberate free radicles which are capable of producing several damages to sensitive organs. Extract carrier lots antioxidant compounds which might be inhibiting this ketone body formation and related tissue toxicity [19].

Diabetes is known to produce cardiovascular complications. Hyperglycemia leads to hypervolumia and it further leads to hypertension. This hypertension, which fluctuates with blood glucose, is very harmful parameter. Cholesterol metabolism gets disturbed and it promotes atherosclerotic plug formation in delicate arteries. When this effect targets coronary artery it may lead to acute sever blockade of this very vital artery [20]. Extract treatment shifted this cholesterol dynamics form bad cholesterol to good cholesterol. Extract treatment reduced cholesterol form LDL, VLDL and TC and increased it into HDL [21]. This change clearly indicates the hypolipidemic potential of this herbal extract. This shift in cholesterol is an important step toward reducing unwanted body weight and controlling obesity [22]. 


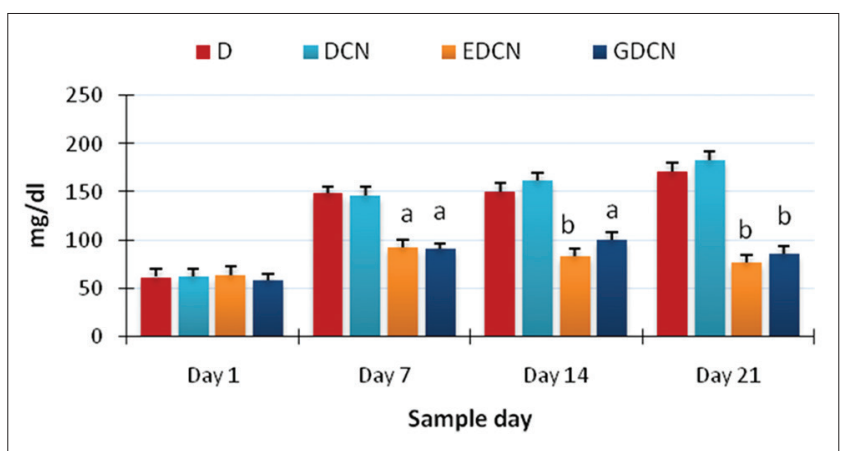

Fig. 3: Serum total cholesterol (n=6). D: Diabetic control group, DCN: Diabetes and caffeine-nicotine both simultaneously, EDCN: Extract-treated caffeine-nicotine diabetic group, GDCN: Glibenclamide-treated caffeine-nicotine diabetic group. Results expressed as mean \pm standard error of mean. Results were compared with diabetic caffeine-nicotine control group; Difference analyzed among groups using one-way ANOVA and Dunnett's t post-test. ${ }^{\text {DDifference between two groups }}$

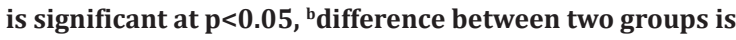
significant at $\mathbf{p}<0.01$, ${ }^{x}$ difference among plane diabetic group and caffeine-nicotine diabetic control group significant at $\mathrm{p}<0.05$

\section{CONCLUSION}

We conclude that like standard drug glibenclamide, CI extract can be used to treat caffeine-nicotine-induced exaggeration of Type 2 diabetes. Although it is herbal drug, CI extract has better potency and very useful activity profile in controlling blood glucose, proteins, and fats (cholesterol) metabolism. It also resists diabetes-induced weight loss and muscular weakness. CI treatment protects kidney and liver like vital organs which are slowly but progressively damaged by Type 2 diabetes. Hence, we propose that $\mathrm{CI}$ herbal extract is better drug in controlling diabetes Type 2 in addicted patients. This finding is based on animal, i.e., rat experiment; and it must be tested further in human beings by conducting appropriate clinical trial.

\section{ACKNOWLEDGMENTS}

Authors express heartfelt gratitude to "Shri Chanakya Education Society," the management of "Indira College of Pharmacy, Tathawade, Pune" for providing lab facility for this research work. We are also thankful to "PRADO Preclinical Pvt. Ltd., Tathawade, Pune" for providing instruments and lab facility.

\section{REFERENCES}

1. Abate N, Chandalia M. Ethnicity, Type 2 diabetes and migrant Asian Indians. Indian J Med Res 2007;125(3):251-8.

2. Sone H, Mizuno S, Ohashi Y, Yamada N. Type 2 diabetes prevalence in
Asian subjects. Diabetes Care 2004;27(5):1251-2

3. Mohan V, Sandeep S, Deepa R, Shah B, Varghese C. Epidemiology of Type 2 diabetes: Indian scenario. Indian J Med Res 2007;125(3):217-30.

4. Gupta M. Impact of meal replacement on the health status of Type II diabetes. Int J Curr Pharm Res 2014;6(4):79-82.

5. Jorwal P, Verma R, Balhara YP. Psychological health of caregivers of individuals with Type 2 diabetes mellitus: A cross-sectional comparative study. J Soc Health Diabetes 2015;3(2):95-101.

6. Li W, Hui R. Cigarette smoking induces insulin resistance: Partly via ASP-C5L2 pathway? Biosci Hypotheses 2009;2(4):267-9.

7. Kumbhar ST, Une HD, Joshi AM, Wangikar PB. Exaggeration of Type 2 diabetes due to caffeine-nicotine co-administration: A study in rats. Int J Pharm Pharm Sci 2016;8(9):277-81.

8. Modak M, Dixit P, Londhe J, Ghaskadbi S, Devasagayam TP. Indian herbs and herbal drugs used for the treatment of diabetes. J Clin Biochem Nutr 2007;40(3):163-73.

9. Rahmatullah M, Mollik MA, Azam AT, Islam MR, Chowdhury MA, Jahan R, et al. Ethnobotanical survey of the Santal tribe residing in Thakurgaon District, Bangladesh. Am Eurasian J Sustain Agric 2009;3(3):889-98

10. Purintrapiban J, Suttajit M, Forsberg NE. Differential activation of glucose transport in cultured muscle cells by polyphenolic compounds from Canna indica L. root. Biol Pharm Bull 2006;29(10):1995-8.

11. Mishra S, Yadav A, Singh SK. A review on Canna indica Linn: Pharmacognostic and pharmacological profile. J Harmon Res Pharm 2013;2(2):131-44.

12. Al-Snafi AE. Bioactive components and pharmacological effects of Canna indica - an overview. Pharm Toxicol 2015;5(2):71-5.

13. Eddouks M, Bidi A, El Bouhali B, Hajji L, Zeggwagh NA. Antidiabetic plants improving insulin sensitivity. J Pharm Pharmacol 2014;66(9):1197-214.

14. Kim Y, Keogh JB, Clifton PM. Polyphenols and glycemic control. Nutrients 2016;8(1). pii: E17.

15. Kumbhar ST, Une HD, Patil SP, Joshi AM. Antidiabetic and hypolipidemic potential of hydroalcoholic extract of Canna indica L. root and rhizomes in rat. Eur J Pharm Med Res 2016;4(1):480-9.

16. Skovsø S. Modeling Type 2 diabetes in rats using high fat diet and streptozotocin. J Diabetes Investig 2014;5(4):349-58.

17. Matta SG, Balfour DJ, Benowitz NL, Boyd RT, Buccafusco JJ, Caggiula AR, et al. Guidelines on nicotine dose selection for in vivo research. Psychopharmacology (Berl) 2007;190(3):269-319.

18. Betteridge DJ. Diabetic dyslipidaemia. Diabetes Obes Metab 2000;2 Suppl 1:S31-6.

19. Hahn SJ, Park JH, Lee JH, Lee JK, Kim KA. Severe hypertriglyceridemia in diabetic ketoacidosis accompanied by acute pancreatitis: Case report. J Korean Med Sci 2010;25(9):1375-8.

20. Castelli WP, Garrison RJ, Wilson PW, Abbott RD, Kalousdian S, Kannel WB. Incidence of coronary heart disease and lipoprotein cholesterol levels. The framingham study. JAMA 1986;256(20):2835-8.

21. Dhaliwall C, Erinmacpherson, Richardson J. Effectiveness of telephone-delivered interventions for increasing physical activity levels in persons with Type 2 diabetes or hypertension: A systematic review. J Crit Rev 2015;2(4):6-11.

22. Mbaoji FN, Ezike AC, Nworu CS, Onyeto CA, Nwabunike IA, Okoli IC, et al. Antioxidant and hepatoprotective potentials of Stemonocoleus micranthus harms (Fabaceae) stem bark extract. Int J Pharm Pharm Sci 2016;8(7):47-51. 